\title{
Lighting the Way to Greener Chemistry: Incandescent Floodlights as a Facile UV Light Source for Classic and Cutting-Edge Photoreactions
}

\author{
Katelyn Randazzo, Zhihan Wang, Zijun D. Wang, Jonathan Butz, and Qianli Rick Chu* \\ Department of Chemistry, University of North Dakota, Grand Forks, ND 58202, USA
}

Total pages: 10

Total tables: 2

Total figures: 10

\section{Table of Contents}

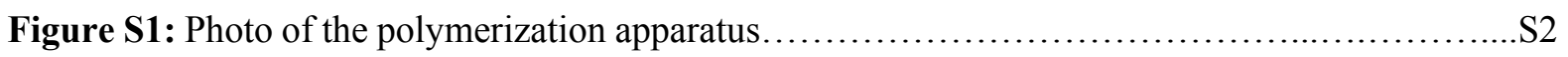

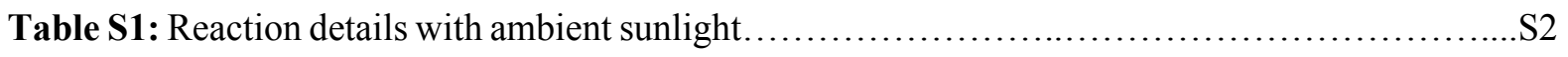

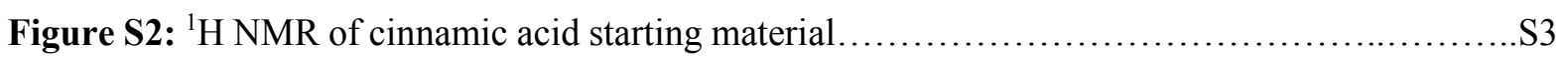

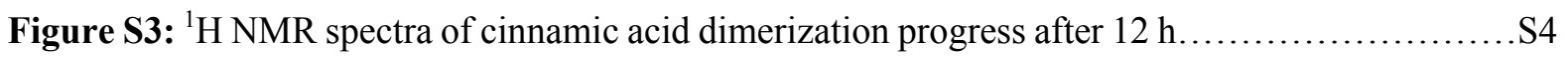

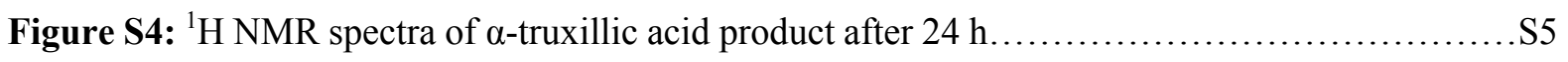

Figure S5: UV/Vis absorption of starting materials (measured in $\mathrm{MeOH}$ solvent).................S6

Figure S6: UV/Vis absorption of starting materials (measured in $\mathrm{CH}_{3} \mathrm{CN}$ solvent) .................S6

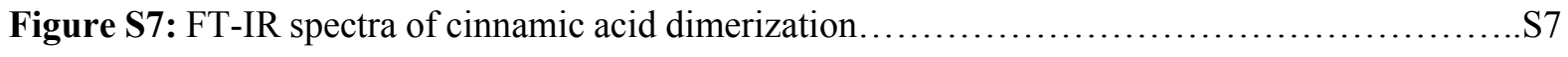

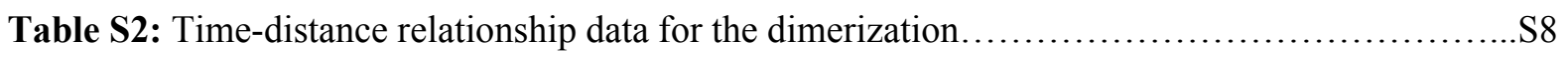

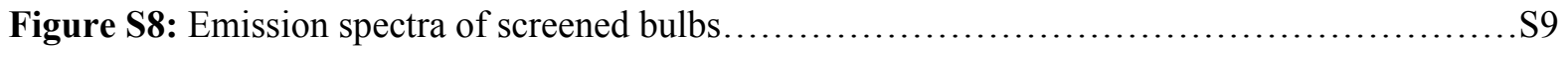

Figure S9: Emission spectra of recommended bulb at varying distances....................S10

Figure S10: UV emission spectra of recommended bulb at varying distances...................S10 


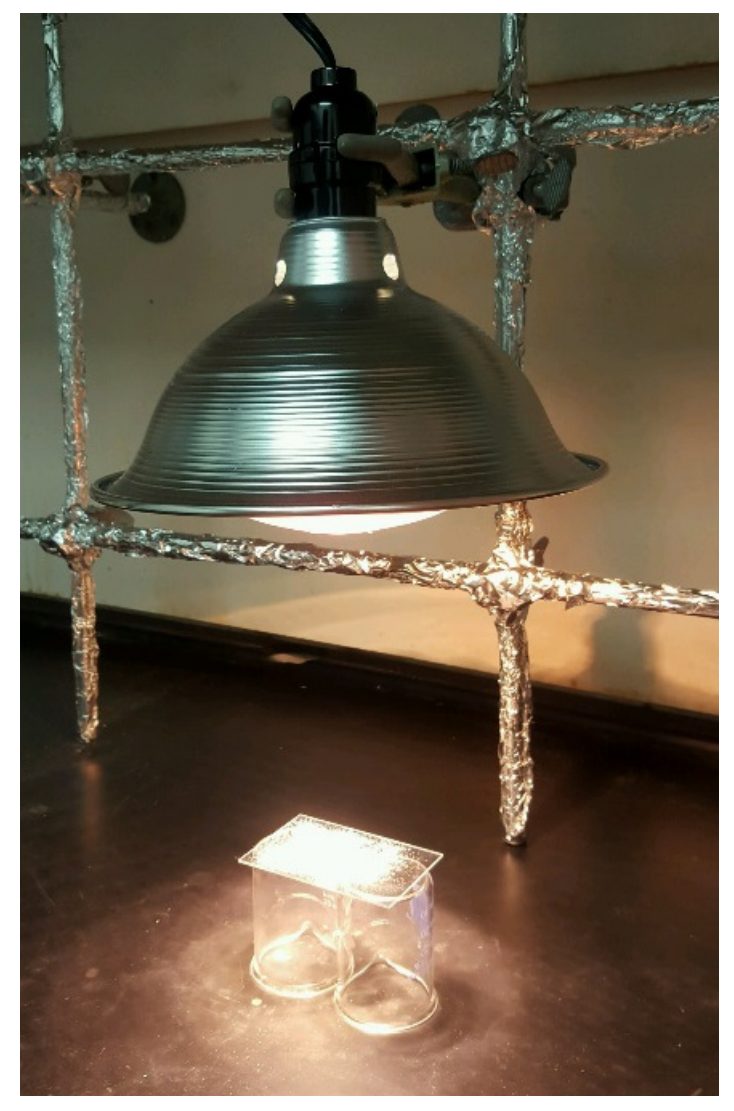

Figure S1. Experimental apparatus consisting of a $150 \mathrm{~W}$ General Electric Floodlight w/ Saf-t-Gard, where the distance between bulb surface and sample is approximately $15 \mathrm{~cm}$.

Table S1. Summary of weather conditions and other details for the reactions carried out under ambient sunlight. All reactions were carried out at the University of North Dakota in Grand Forks, ND $\left(47.92^{\circ} \mathrm{N}\right.$, $\left.97.06^{\circ} \mathrm{W}\right)$.

\begin{tabular}{cccccc}
\hline Date & Sky Conditions & Start Time/Temp & $\begin{array}{c}\text { End } \\
\text { Time/Temp }\end{array}$ & $\begin{array}{c}\text { Reaction } \\
\text { Time }\end{array}$ & Peak Temp \\
\hline $5 / 1 / 16$ & Clear & $11 \mathrm{am} / 58^{\circ} \mathrm{F}$ & $4 \mathrm{pm} / 66^{\circ} \mathrm{F}$ & $5 \mathrm{~h}$ & $66^{\circ} \mathrm{F}$ \\
\hline $5 / 3 / 16$ & Clear & $11 \mathrm{am} / 64^{\circ} \mathrm{F}$ & $4 \mathrm{pm} / 67^{\circ} \mathrm{F}$ & $5 \mathrm{~h}$ & $67^{\circ} \mathrm{F}$ \\
\hline $5 / 8 / 16$ & Clear & $11 \mathrm{am} / 67^{\circ} \mathrm{F}$ & $3 \mathrm{pm} / 76^{\circ} \mathrm{F}$ & $4 \mathrm{~h}$ & $77^{\circ} \mathrm{F}$ \\
\hline
\end{tabular}




\section{Starting Material}<smiles>O=C(O)/C=C/c1ccccc1</smiles>

\section{trans-Cinnamic acid}
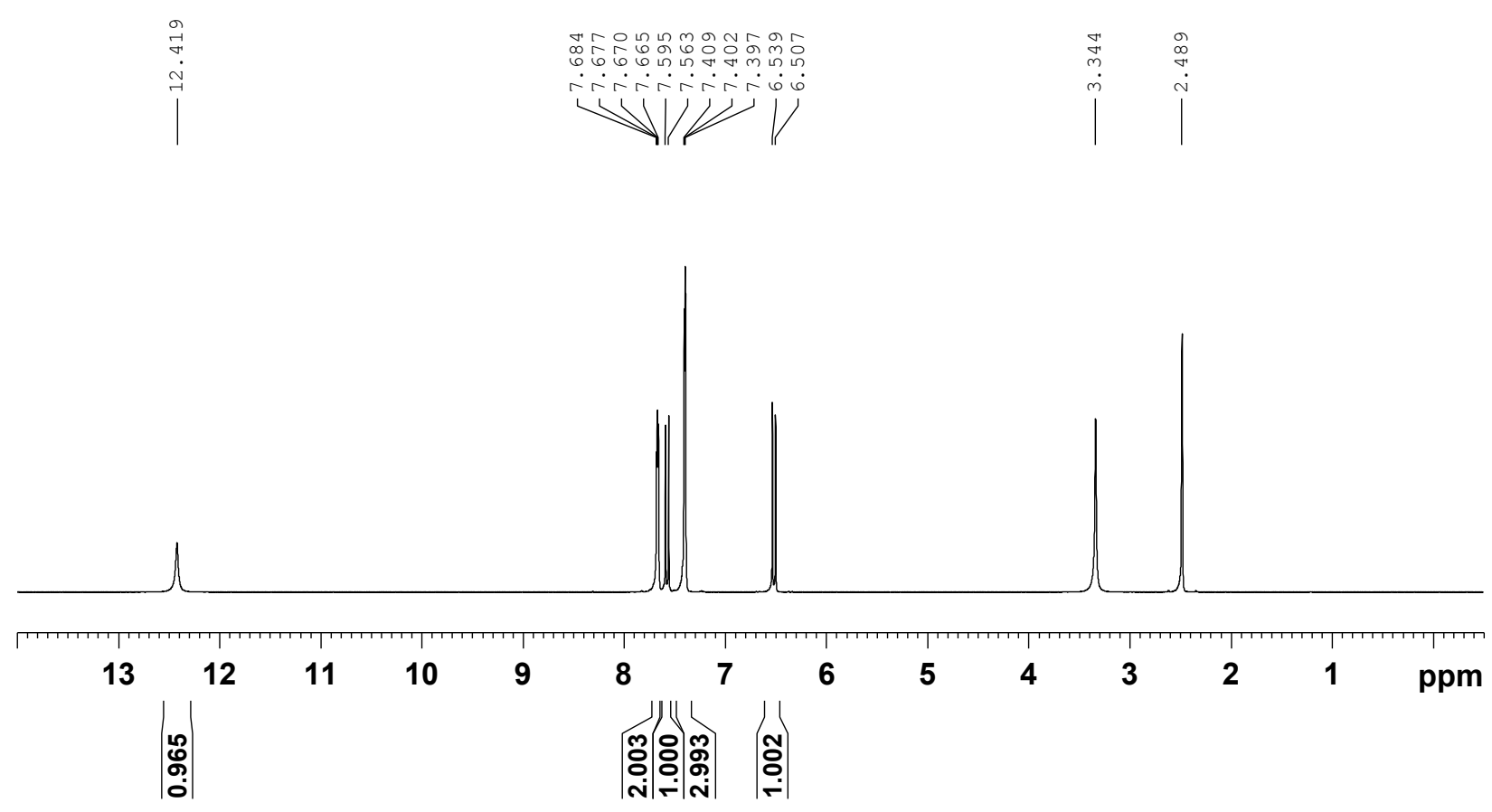

Figure S2. ${ }^{1} \mathrm{H}$ NMR spectra for the trans-cinnamic acid starting material. 


\section{$12 \mathrm{~h}$ irradiation}<smiles>O=C(O)/C=C/c1ccccc1</smiles>

trans-Cinnamic acid
$\&$<smiles>O=C(O)C1CC(c2ccccc2)CC1C(=O)O</smiles>

$\alpha-$ Truxillic acid

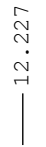
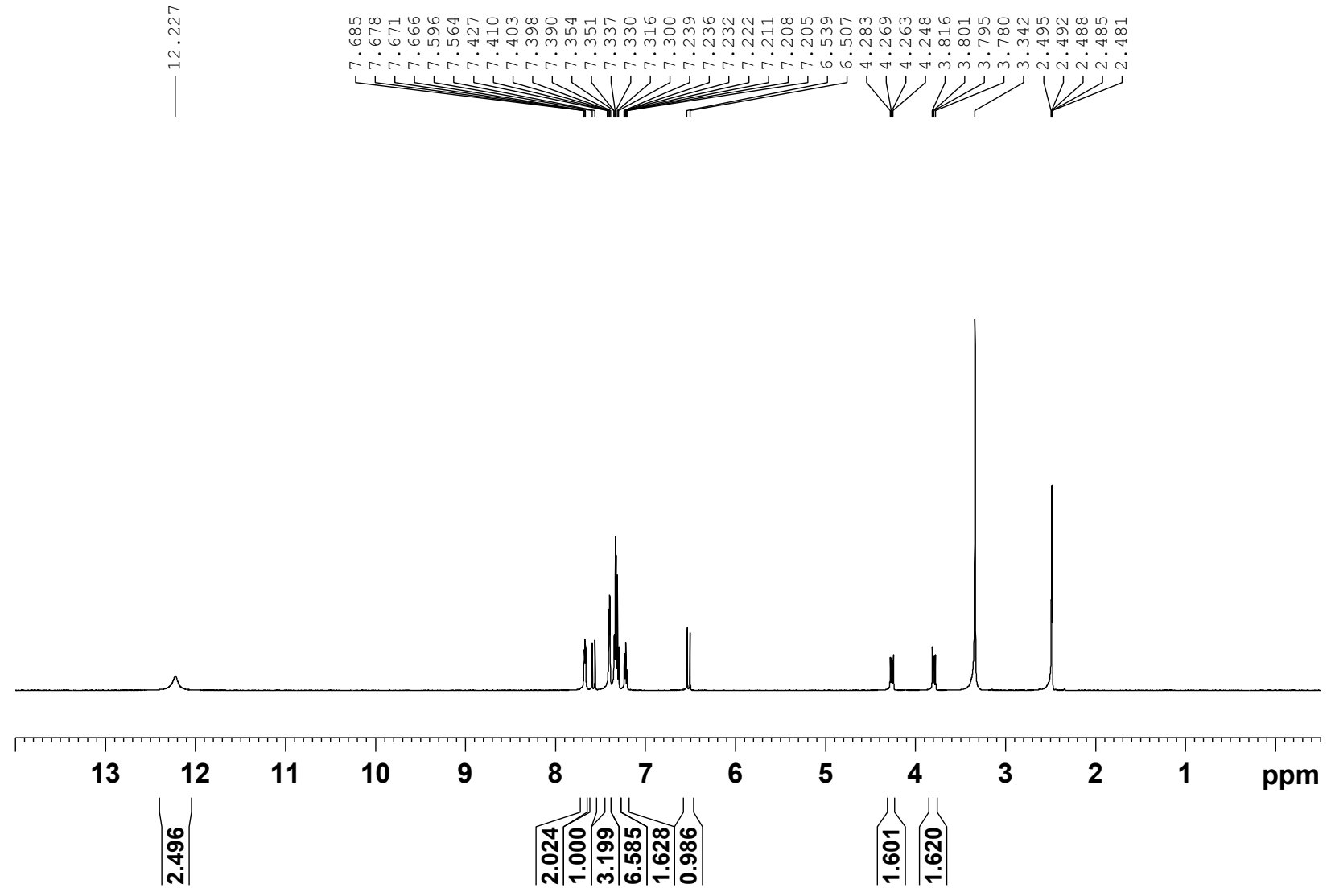

Figure S3. ${ }^{1} \mathrm{H}$ NMR spectra taken after 12 hours of irradiation showing the $\alpha$-truxillic acid product and the unreacted trans-cinnamic acid starting material. 


\section{$24 \mathrm{~h}$ irradiation}<smiles>O=C(O)C1C(c2ccccc2)CCC1c1ccccc1</smiles>

\section{$\alpha$-Truxillic acid}

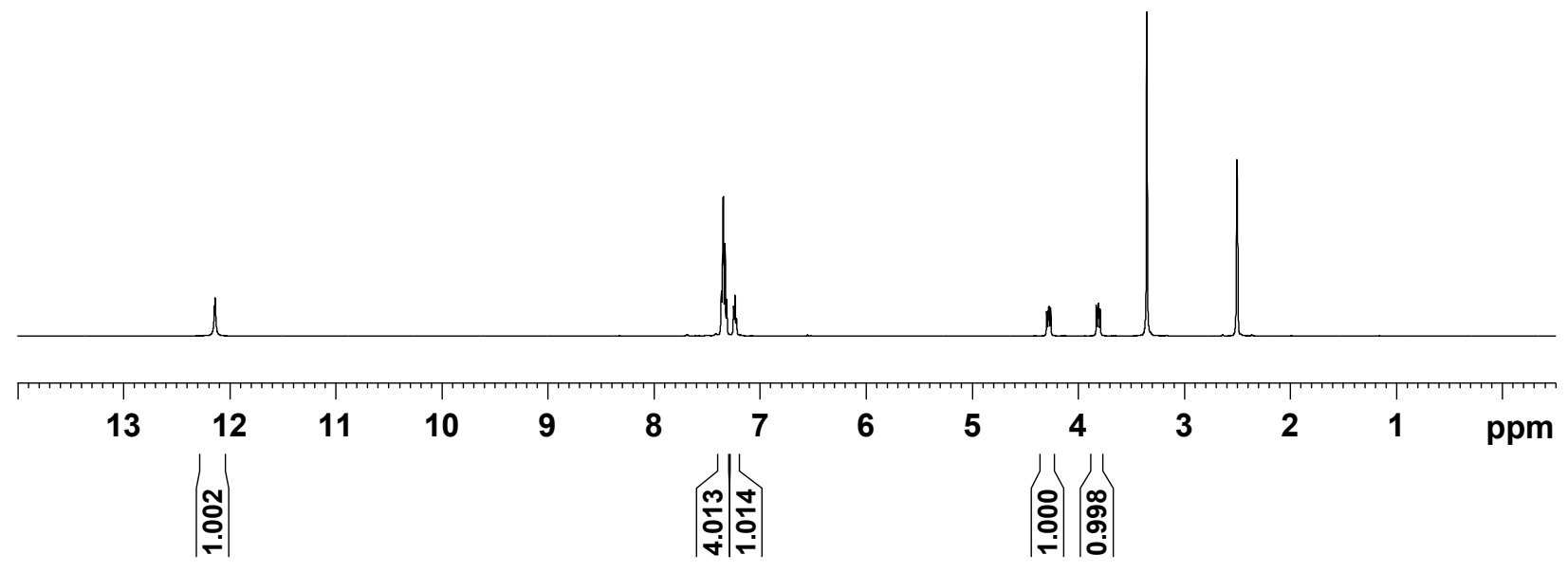

Figure S4. ${ }^{1} \mathrm{H}$ NMR spectra taken after 24 hours of irradiation showing the $\alpha$-truxillic acid product. 


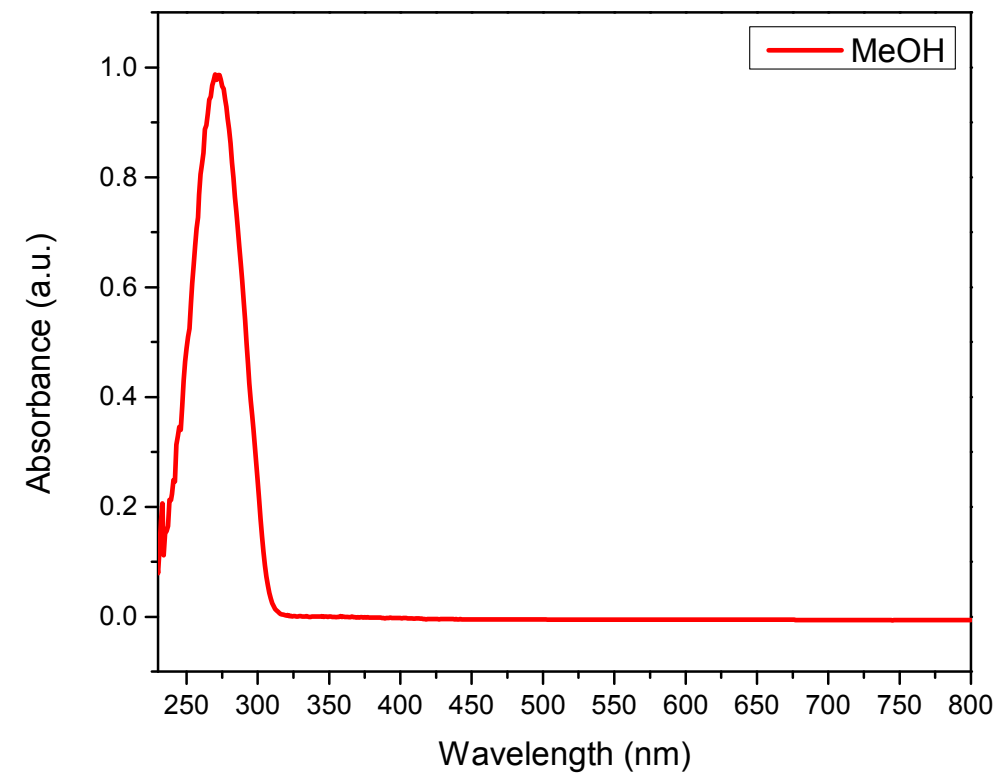

Figure S5. UV-Vis spectrum for the trans-cinnamic acid starting material, measured in a MeOH solvent.

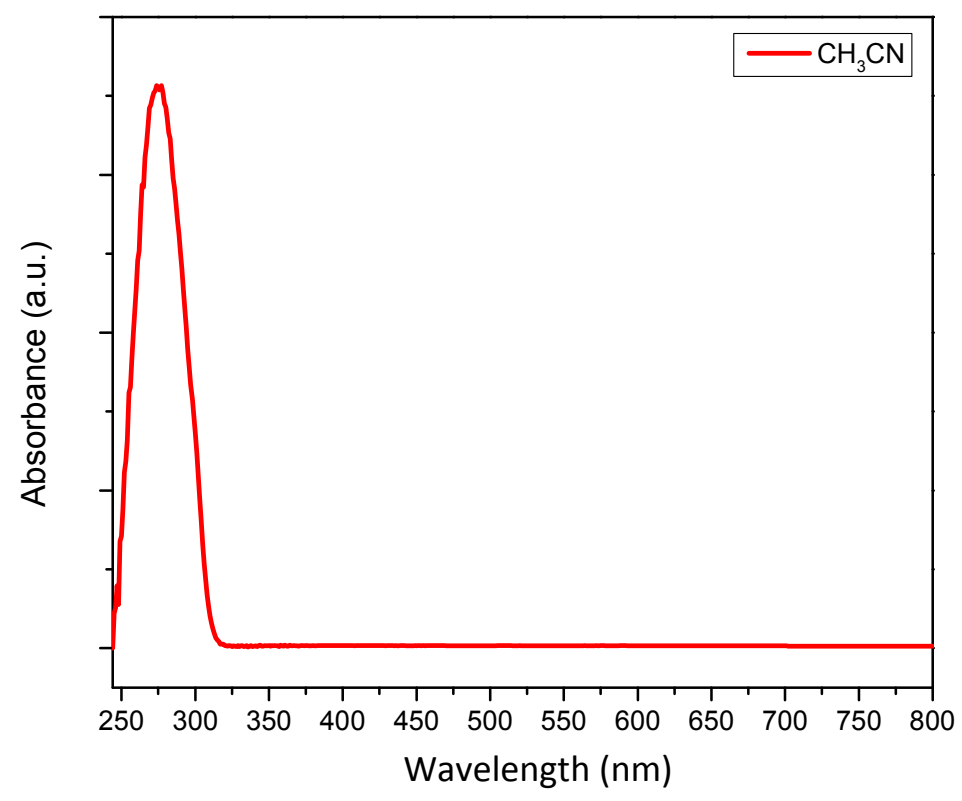

Figure S6. UV-Vis spectrum for the monomer of the 2D polycyclobutane, measured in a $\mathrm{CH} 3 \mathrm{CN}$ solvent. 


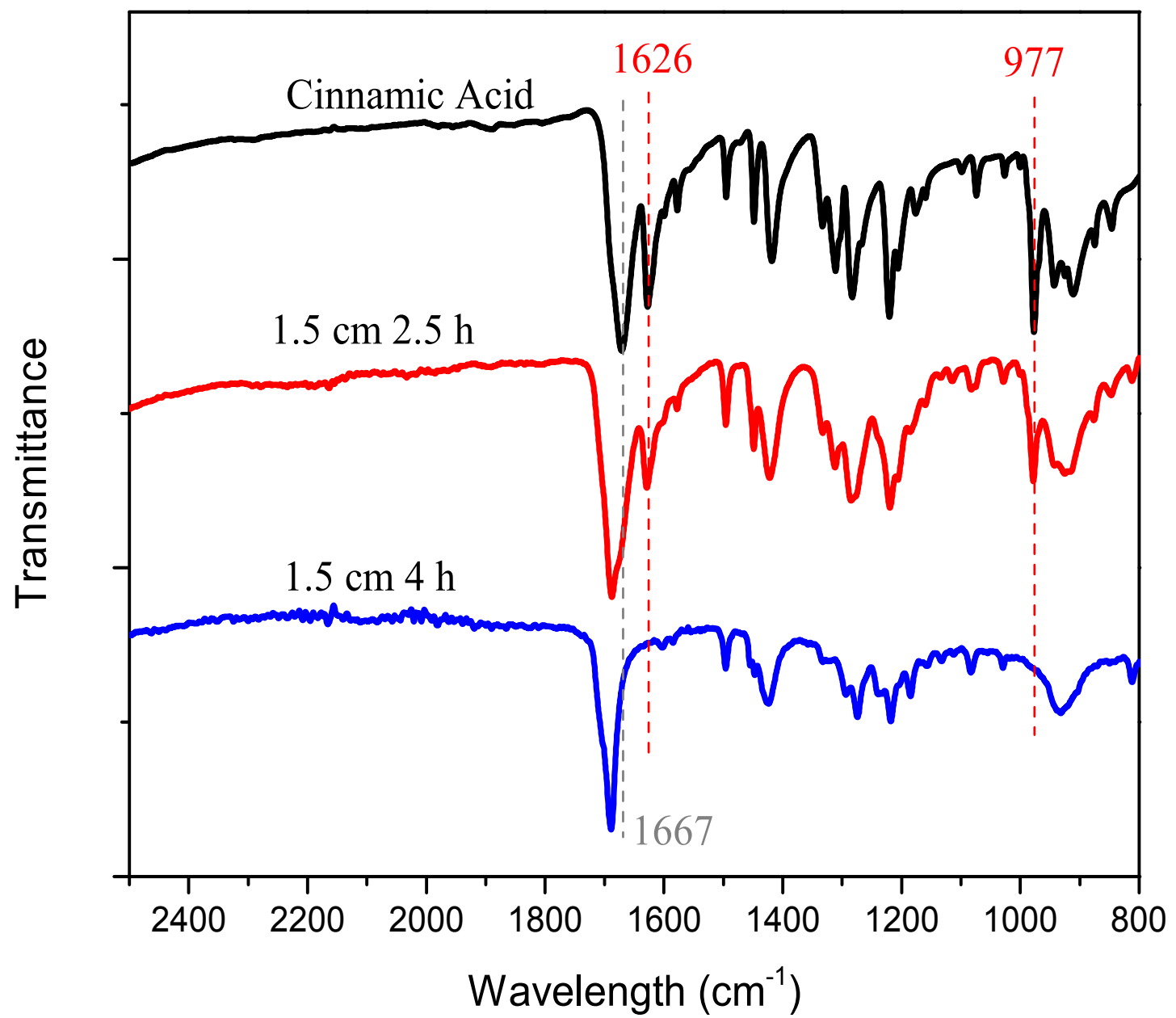

Figure S7. FT-IR spectra for the progress of the dimerization of trans-cinnamic acid to form $\alpha$-truxillic acid. 
Table S2. Summary of the reaction of finely ground trans-cinnamic acid to $\alpha$-truxillic acid using a $150 \mathrm{~W}$ General Electric Floodlight w/ Saf-t-Gard.

\begin{tabular}{cccc}
\hline Entry & Distance (cm) & Temperature $\left({ }^{\circ} \mathbf{C}\right)$ & Time (h) \\
\hline 1 & 1.5 & 52.0 & 4 \\
\hline 2 & 3 & 47.5 & 12 \\
\hline 3 & 5 & 44.0 & 22 \\
\hline 4 & 8 & 43.0 & 37 \\
\hline 5 & 11 & 40.5 & 77 \\
\hline 6 & 14 & 36.0 & 108 \\
\hline 7 & 17 & 34.0 & 156 \\
\hline 8 & 20 & 31.0 & 252 \\
\hline 9
\end{tabular}




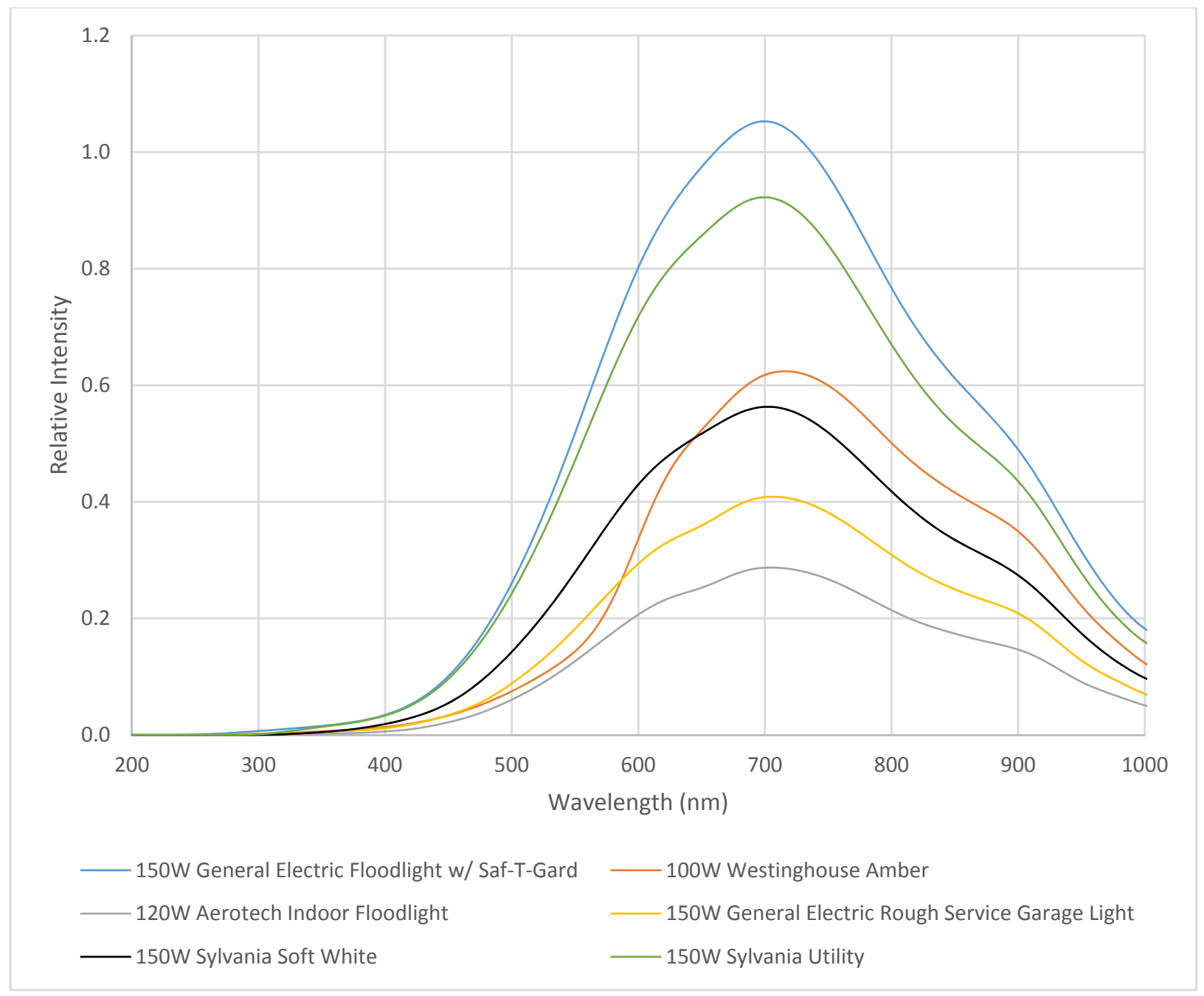

Figure S8. Emission spectra for screened bulbs obtained using a Thorlabs CCS200 spectrometer with Thorlabs CCSA2 cosine corrector. Emission was measured from a distance of $3 \mathrm{~cm}$ for all bulbs. 


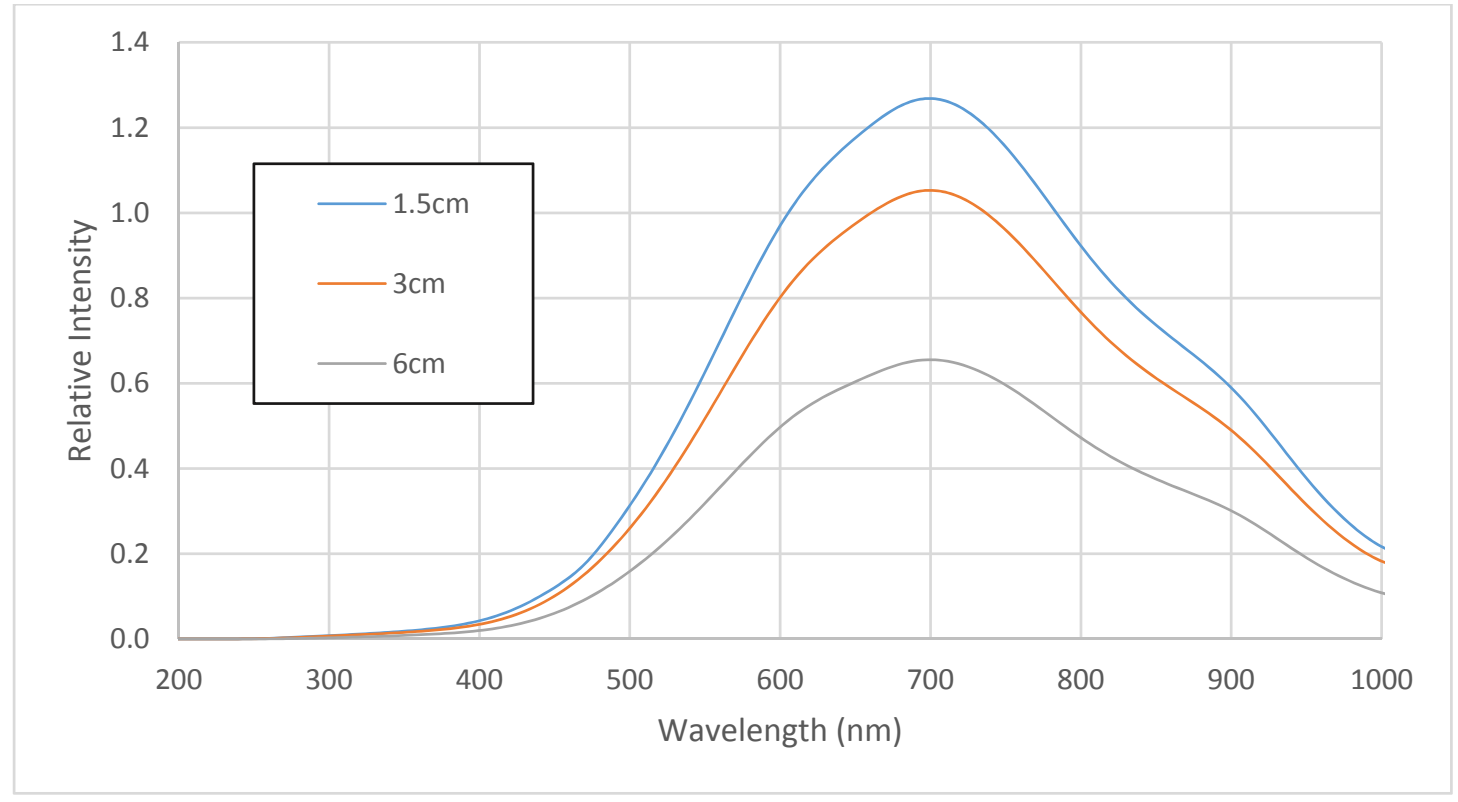

Figure S9. Emission spectra for the recommended 150W General Electric Floodlight w/ Saf-T-Gard taken from a distance of $1.5 \mathrm{~cm}, 3 \mathrm{~cm}$, and $6 \mathrm{~cm}$.

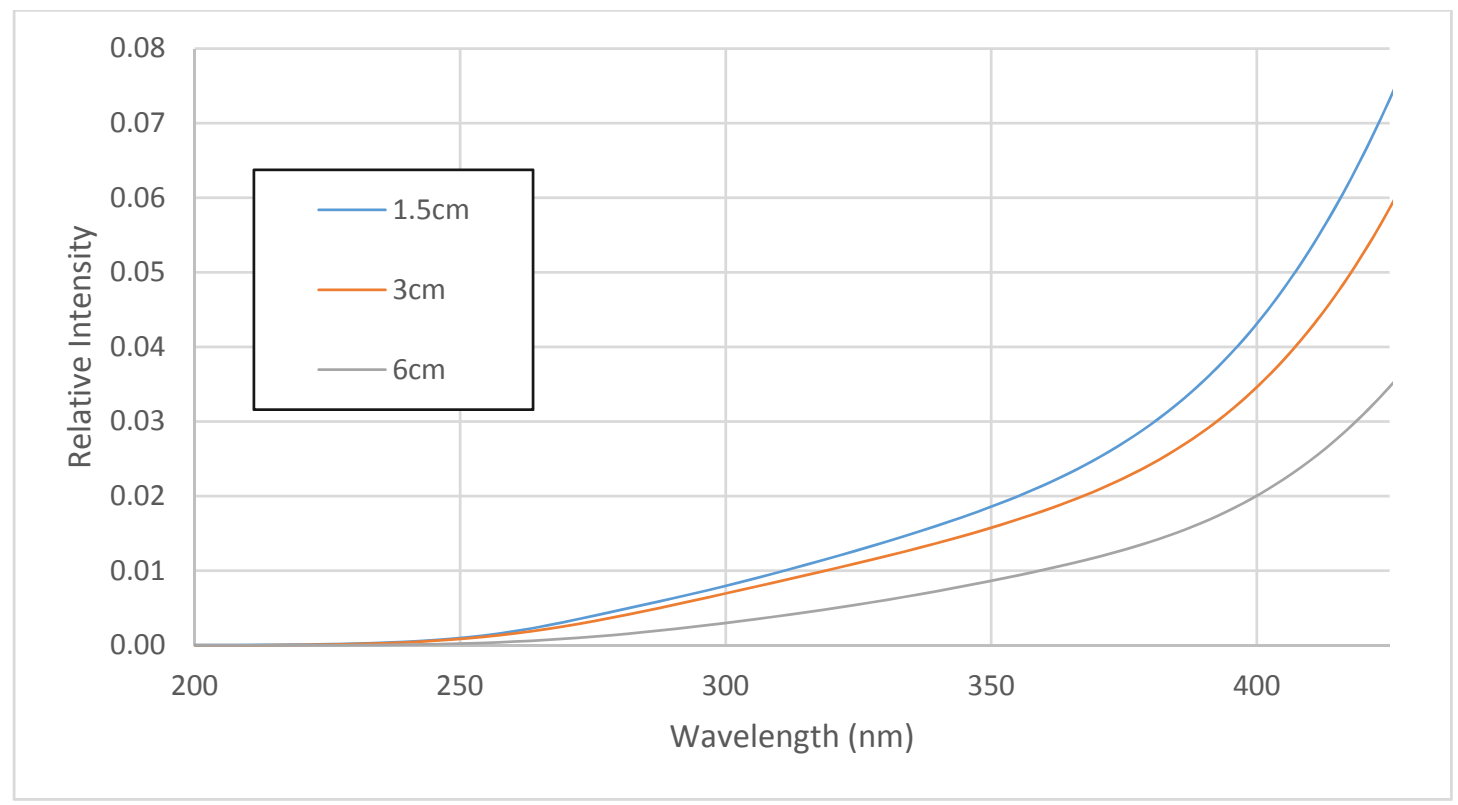

Figure S10. Ultraviolet emission spectra for the recommended $150 \mathrm{~W}$ General Electric Floodlight w/ SafT-Gard taken from a distance of $1.5 \mathrm{~cm}, 3 \mathrm{~cm}$, and $6 \mathrm{~cm}$. 